\title{
Immunofunctional Assay of Human Growth Hormone (hGH) in Serum: A Possible Consensus for Quantitative hGH Measurement*
}

\author{
CHRISTIAN J. STRASBURGER, ZIDA WU†, CLAUS-DIETER PFLAUM, AND \\ REGINA A. DRESSENDÖRFER \\ Medical Clinic, Innenstadt University Hospital, Ludwig Maximilians University, Munich, Germany
}

\begin{abstract}
Confirmation of the diagnosis of GH deficiency in adults and children involves provocative testing for human (h) $\mathrm{GH}$. Different commercially available immunoassays yield largely discrepant results in the measurement of GH levels in human serum. These discrepancies result in doubtful relevance of cut-off levels proposed for $\mathrm{GH}$ provocative testing. We have developed an immunofunctional assay method that allows quantitation of only those $\mathrm{GH}$ forms in circulation that possess both binding sites of the hormone for its receptor and thus can initiate a biological signal in target cells. An anti-hGH monoclonal antibody recognizing binding site 2 of hGH is immobilized and used to capture hGH from the serum sample. Biotin-labeled recombinant GH-binding protein in a second incubation step forms a complex with those hGH molecular isoforms that have both binding sites for the
\end{abstract}

receptor. The signal is detected after a short third incubation step with labeled streptavidin. The assay is sensitive (detection range, $0.1-100 \mu \mathrm{g} / \mathrm{L}$ ) and has average inter- and intraassay precisions of $10.3 \%$ and $7.3 \%$, respectively. Endogenous GH-binding protein does not interfere with the hGH result; placental lactogen shows no detectable cross-reaction in this immunofunctional assay. The degree of immunofunctionally active hGH forms in serum samples, calculated by comparison of immunofunctional assay and RIA results, varied between $52-93 \%$. We propose this immunofunctional assay for GH measurement as a new reference method for hGH quantitation in serum. The immunofunctional assay translates only hGH forms into an assay signal that are capable of dimerizing $\mathrm{GH}$ receptors and, thus, of initiating a biological effect in target cells. (J Clin Endocrinol Metab 81: 2613-2620, 1996)
$\mathrm{T}$ HE DETERMINATION of circulating levels of human (h)GH in serum is generally accomplished by the use of commercially available immunoassay kits. The comparative measurement of serum samples by different immunoassay kits results in vastly discrepant results, although most commercial immunoassay kits for GH determination are calibrated against international reference preparations of the hormone (1-3). This heterogeneity of hGH concentrations measured by different immunoassay kits has been attributed to the use of different reference preparations (4), to the heterogeneity of different forms of $\mathrm{GH}$ in circulation $(5,6)$, the epitope specificity of the antibodies employed (7), and differences in standard matrix (8).

The diagnostic procedures in the evaluation of suspected GH deficiency in childhood $(9,10)$ and recently also in adult patients (11) involve GH measurement after provocative tests. The results obtained by these measurements have profound effects on establishment of the diagnosis and represent the key criteria for reimbursement of the GH replacement therapy costs. Although recommendations exist concerning the provocative testing procedures for the diagnosis of $\mathrm{GH}$

Received September 19, 1995. Revision received February 7, 1996. Accepted February 12, 1996.

Address all correspondence and requests for reprints to: Dr. C. J Strasburger, Division of Ncuroendocrinology, Mcdical Clinic, Innenstadt University Hospital, Ziemssenstrrasse 1, 80336 Munich, Germany.

* Presented in part at the 77th Annual Meeting of The Endocrine Society, June 14-17, 1995, Washington, D.C. (Abstract P1-189).

t Supported in part by a fellowship from the Hans-Seidel-Stiftung.

$\ddagger$ Supported by Grant 50WB93760 from Bundesministerium für Forschung und Technologie/Deutsche Agentur für RaumtahrtAngelegenheiten. deficiency, and cut-off levels have been proposed below which the peak GH levels after provocative tests should be, no consensus has been achieved or proposed for the biochemical procedure of $\mathrm{GH}$ measurement itself.

The essential information requested by blood sampling for $\mathrm{GH}$ determination is the amount of biologically active, functional GH in the circulation at the time of blood sampling. The answer commonly provided by the analytical results, in contrast, represents a quantitation of immunoreactive $\mathrm{GH}$ molecular forms in the sample, to which variants, fragments, and aggregates of GH (6) contribute to different extents depending on the epitope specificity of the antibodies employed in the assay $(1,12)$.

hGH has been shown to induce dimerization of its receptor as the initial step of signal transduction in target cells (13), which leads to phosphorylation of the intracellular domain of the hGH receptor and receptor-associated proteins (14). This process initiates the signal transduction cascade involving JAK2 kinase and STAT (Signal Transducence and Activation of Transcription) proteins $(15,16)$. The $x$-ray crystallography structure of a complex formed by one molecule of $\mathrm{GH}$ and two GH receptor ecto domains was resolved (17), and the epitopes of the hGH molecule interacting with either receptor molecule have been characterized. The GH molecule sequentially binds to a first receptor molecule with a large contact surface area involving a total of 31 amino acid side-chains (18) of the C-terminal part of the fourth helix bundle, parts of the random coil sequence between helix 1 and helix 2 , and parts of helix $1(13,19)$. Consecutively, this 1:1 complex associates a second receptor molecule via binding site 2 of hGH, which represents a much smaller surface 
area on the $\mathrm{N}$-terminal random coil sequence, the beginning of helix 1 and C-terminal parts of helix 3 of the hGH molecule (13).

We have sought to identify monoclonal antibodies (mAbs) specific for both binding domains on the $\mathrm{hGH}$ molecule that interact with the receptor molecules and attempted to design an immunoassay procedure more closely reflecting in its results the biologically active proportion of $\mathrm{GH}$ in a given serum sample (7). As the epitope recognized by mAbs generally spans over 3-10 amino acid residues (20), no single $\mathrm{mAb}$ could be identified representatively binding to the 31 amino acid side-chains involved in interaction on binding site 1 with the receptor (18).

This article describes our approach to design an immunofunctional assay (IFA) for hGH in which only those molecular forms of hGH in the sample to be analyzed translate into an assay signal that is also capable of inducing a receptor dimerization and thereby initiating the signal transduction process on target cells. The IFA is based on the interaction of GH with an immobilized mAb specific for binding site 2 of the hormone and with biotin-labeled recombinant hGH (rhGH)-binding protein (hGHBP), which represents the fulllength $\mathrm{GH}$ receptor ecto domain.

\section{Materials and Methods}

\section{Reagents}

Twenty-two-kilodalton rhGH, 20-kDa rhGH, and rhGH dimers were provided by Eli Lilly Co. (Indianapolis, IN). The recombinant reference preparation 88/624 of hGH was obtained from NIBSC (Hartfordshire, UK). Defined fragments of hGH derived from enzymatic or chemical cleavage were kindly donated by Dr. Jack Kostyo (Ann Arbor, MI). Recombinant mutants of hGH lacking the first 7 or 13 amino acid residues, respectively, were gifts from Dr. Tikva Vogel, Biotechnology General (Nesziona, Israel). A recombinant variant of $\mathrm{hGH}$ in which the C-terminal 9 of 13 amino acids that are heterologous between pituitary hGH and placental GH are mutated to the placental variant with the remainder of the sequence according to the pituitary $\mathrm{GH}$ was a gift from Dr. Pär Gellerfors, Kabi Pharmacia (Stockholm, Sweden). Pituitary-derived 22-kDa hGH (AFP-4793B), 20-kDa hGH (AFP-4286B), and polyclonal anti-GH serum from rabbit (AFP-C11981A) were gifts from Dr. A. F. Parlow, NIDDK, Harbor-University of Calfiornia-Los Angeles Medical Center (Torrance, CA). Full-length rhGH receptor ecto domain (amino acids 1-246) was expressed in Escherichia coli by Dr. G. Crivi, SearleMonsanto (St. Louis, MO) and extracted and refolded from inclusion bodies by Dr. A. Gertler (Rehovot, Israel). I Iuman placental lactogen (hPL) was purchased from Sigma (Deisenhofen, Germany), and sheep serum was obtained from Paa Biologics (Marburg, Germany). All other reagents were of analytical grade.

mAbs to hGH were produced by the myeloma technique (21) and propagated in protein-free medium (PFHM II, Life Technologies, Eggenstein, Germany). Anti-hGH mAb 7B11 is IgG subtype 1 and has an affinity of $3 \times 10^{9} \mathrm{~L} / \mathrm{mol}$ for $22-\mathrm{kDa} \mathrm{hGH}$.

\section{Biotinylation of rhGH and rhGHBP}

Biotin- $\epsilon$-amidocaproyl- $\gamma$-butyryl- $N$-hydroxysuccinimide ester was added in a 20 -fold molecular excess to either rhGH or rhGHBP following the protocols described previously (22). The reaction mixtures were left for $2 \mathrm{~h}$ at ambient temperature and then applied to a Superdex 30 fast protein liquid chromatography column for separation of labeled protein and uncoupled biotin. The biotinylated proteins were stored in 0.2 $\mathrm{mmol} / \mathrm{L}$ Tris- $\mathrm{HCl}$ buffer, $\mathrm{pH} 7.4$, containing $1 \% \mathrm{BSA}$ in aliquots at $-20 \mathrm{C}$.

\section{End-point detection}

Using biotin as a primary probe throughout, the microtiter plates with an immobilized reaction partner and a biotinylated assay component were washed three times with $0.3 \mathrm{~mL}$ wash buffer $(50 \mathrm{mmol} / \mathrm{L}$ $\mathrm{Na}_{2} \mathrm{HPO}_{4}, 2 \%$ Tween-40, and $0.1 \% \mathrm{NaN}_{3}, \mathrm{pH} 7.5$ ) and then incubated for $30 \mathrm{~min}$ with $10 \mathrm{ng}$ / well europium-labeled streptavidin (Wallac, Turku, Finland) in assay buffer [ $50 \mathrm{mmol} / \mathrm{L}$ Tris-(hydroxymethyl)-aminomethane, $9 \mathrm{~g} / \mathrm{L} \mathrm{NaCl}, 0.5 \mathrm{~g} / \mathrm{L} \mathrm{NaN}_{3}, 0.1 \mathrm{~g} / \mathrm{L}$ Tween- $40,5 \mathrm{~g} / \mathrm{L} \mathrm{BSA}, 0.5 \mathrm{~g} / \mathrm{L}$ bovine $\gamma$-globulin, and $20 \mu \mathrm{mol} / \mathrm{L}$ diethylenetriaminepenta acetic acid, $\mathrm{pH}$ 7.75]. After a 6-fold wash step, the microtiter plates were filled with $0.2 \mathrm{~mL}$ enhancement solution (Wallac) to transchelate europium into a highly fluorescent complex. After 5-15 min of agitation on a horizontal shaker, the plate was placed into a Delfia 1232 time-resolved fluorometer to read the signal.

\section{Identification of epitopes recognized by anti-hGH $m A$ bs}

More than $40 \mathrm{mAbs}$ have been produced in our laboratory by immunization of $\mathrm{BALB} / \mathrm{c}$ mice with recombinant $22-\mathrm{kDa} \mathrm{GH}$ in addition to anti-hGH-mAbs, previously reported (23). Antibodies were selected to have affinities $\left(\mathrm{K}_{\mathrm{a}}\right)$ for $\mathrm{hGH}$ of $10^{9} \mathrm{~L} / \mathrm{mol}$ or more. The epitope specificities of the anti-hGH mAbs were characterized by performing comparative displacement experiments in which the respective antibodies were immobilized to polystyrene surfaces, and the $50 \%$ intercept for displacement of biotin-labeled hGH by $22-\mathrm{kDa}$ GH was compared to the $50 \%$ intercept of $\mathrm{hGH}$ fragments and $\mathrm{hGH}$ variants. By analysis of the cross-reactivity of a given monoclonal antibody with these hGHrelated forms and projection of the structural alterations in the hGH variants or fragments onto the structural model of the $22-\mathrm{kDa} h \mathrm{hH}$ molecule derived from $x$-ray crystallography analysis $(17,24)$, the respective epitopes were deduced.

\section{hGH-IFA assay standards and patient samples}

hGH calibrators containing pituitary-derived hGH in sheep serum were purchased from Medgenix (Fleurus, Belgium). Twenty-two kilodalton rhGH reference preparation $88 / 624$, containing $2 \mathrm{mg} /$ ampule, was dissolved and diluted in sheep serum or a pool of human serum previously shown to contain less than $0.1 \mu \mathrm{g} / \mathrm{L} \mathrm{hGH}$, as measured by in-house sandwich immunoassay.

Patient sera were obtained after written informed consent from patients with postoperative hypopituitarism undergoing provocative testing for hGH secretion and under $\mathrm{GH}$ replacement therapy as well as from patients with active acromegaly undergoing treatment with somatostatin analogs as well as from sera sent into the pituitary hormone laboratory of our university hospital for routine hGH measurement.

\section{Reference hGH immunoassay}

A competitive polyclonal RIA was performed by use of the polyclonal antibody provided by the NIDDK (anti-hGH-2) raised in rabbit, following the procedure suggested by the NIDDK, but using ${ }^{125} \mathrm{I}$-labeled recombinant hGH produced by the Iodogen method (25) to a specific activity of $82 \mu \mathrm{Ci} / \mu \mathrm{g}$.

\section{$N b 2$ cell bioassay for $h G H$ quantification}

$\mathrm{The} \mathrm{Nb} 2$ assays were carried out in the Section of Pediatric Endocrinology at the Universitäts-Kinderklinik (Tubingen, Germany). Nb2 c11 cells and anti-hPRL monoclonal antibody $9 \mathrm{C} 3$ as ascites fluid were kindly provided by Dr. H. Friesen (Winipeg, Canada). The cells were expanded in Fischer's medium with $10 \%$ FCS and transferred to Fischer's medium with $5 \%$ horse serum $48 \mathrm{~h}$ before assay [method modified after that of Tanaka et al. (26)]. Two $\times 10^{5}$ cells were plated in 24-well microtiter plates and grown in the presence of hGH standard of seven concentrations between $0-24.5 \mu \mathrm{g} / \mathrm{L}$ or in human serum in the presence of a 1:8000 dilution of the anti-hPRL antibody $9 \mathrm{C} 3$ for $72 \mathrm{~h}$. The standards were calibrated against International Reference Preparation 80/505. The cell number was determined by a Coulter counter (Cobas Minos STE, Hoffman LaRoche, Grenzach, Germany), and the number of cell doublings was calculated. For estimation of the hGH concentrations in the serum samples, the rate of doublings obtained in the serum under 
neutralizing conditions of the anti-hPRL antibody was compared to the number of doublings achieved by the standard concentrations of hGH.

\section{IFA procedure}

Anti-hGH mAb 7B11, which binds to an epitope largely overlapping with binding site 2 of the hGH molecule, was adsorbed to 96-well flat bottom microtiter plates (Nunc, Roskilde, Denmark) by incubation of $500 \mathrm{ng} \mathrm{mAb}$ 7B11 in $200 \mu \mathrm{L} 50 \mathrm{mmol} / \mathrm{L}$ sodium phosphale buffer, $\mathrm{pH}$ 9.6. The plates were sealed with a self-adhesive cover film and stored at $4 \mathrm{C}$ for $12 \mathrm{~h}$ to 1 month. After aspiration of the coating solution, the plates were washed three times with washing solution.

Twenty-five microliters of standard or sample were pipetted into the wells, followed by $175 \mu \mathrm{L}$ assay buffer. The plates were incubated at ambient temperature for $3 \mathrm{~h}$ on a horizontal shaker. After a 3 -fold wash step, $50 \mathrm{ng} /$ well biotinylated rhGHBP were added in $200 \mu \mathrm{L}$ assay buffer, and the plates were sealed and incubated overnight $(12-16 \mathrm{~h})$ at $4 \mathrm{C}$. After a 3-fold wash step, the plates were incubated with streptavidin-europium and processed as described above. Figure 1 shows the complex of antibinding site 2 antibody mAb $7 \mathrm{~B} 11$ immobilized to the microtiter plate, hGH, and the biotinylated rhGHBP that binds to binding site 1 as well as the streptavidin-europium complex binding to the biotin moiety of this conjugate. The calibration curve was produced by plotting the hGH concentration of standards and the signal from the time-resolved fluorometric end point in a double logarithmic system and using a spline-tit as provided in the Multicalc sottware package (Wallac). Concentrations of unknown samples were read by interpolation of the signal obtained on the standard curve.

\section{Study of interference from endogenous GHBP on hGH IFA results}

To investigate a potential bias produced by endogenous hGHBP on the reading obtained from the hGI IFA, increasing concentrations of rhGHBP were incubated overnight at $4 \mathrm{C}$ with rhGH at concentrations of $1,4,14$, and $40 \mu \mathrm{g} / \mathrm{L}$. rhGHBP concentrations between $500-10,000$ $\mathrm{pmol} / \mathrm{L}$ were used. The reagent mixtures were allowed to form complexes and then assayed in the hGH IFA as unknown samples using a standard curve of rhGH in assay buffer.

\section{Displacement of biotinylated rhGHBP from immobilized $h G H$ by epitope-specific $m A b s$}

mAb $10 \mathrm{A7}\left(\mathrm{IgG}_{1} ; \mathrm{K}_{\mathrm{a}}\right.$ for $\left.22-\mathrm{kDa} \mathrm{hGH}, 6 \times 10^{9} \mathrm{~L} / \mathrm{mol}\right)$ was immobilized on microtiter plates. This antibody was previously identified to bind to an epitope distant from both receptor-binding sites of the hGH molecule. The antibody was loaded with rhGH by incubation of 0.25 $\mathrm{ng} /$ well rhGH in assay buffer for $3 \mathrm{~h}$ at ambient temperature. After a wash step, $50 \mathrm{ng} /$ well biotinylated rhGHBP in the absence or presence

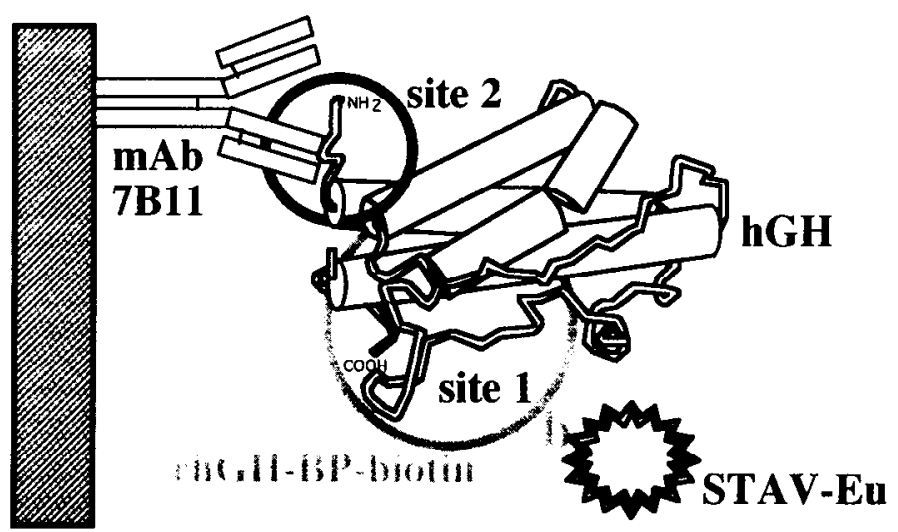

FIG. 1. Assay scheme of the hGH IFA. Immobilized mAb 7B11 binds hGH via its N-terminally located epitope overlapping with binding site 2 . In a second incubation step, biotinylated rhGHBP, which is structurally identical to the hGH receptor ecto domain, binds to the complex, and the biotin moieties link to europium-labeled streptavidin (STAV-Eu). of increasing concentrations of anti-hGH mAb 7B11 binding to binding site 2 of the hGH molecule or of mAb $8 \mathrm{BI} 1$ binding to binding site 1 of the molecule $\left(\mathrm{K}_{\mathrm{a}}\right.$ for $22-\mathrm{kD}$ a $\mathrm{hGH}, 7 \times 10^{9} \mathrm{~L} / \mathrm{mol}$ ) was allowed to incubate overnight at $4 \mathrm{C}$. We hypothesized that two biotinylated molecules of hGHBP could bind to each molecule of hGH. As binding of $\mathrm{hGH}$ receptors to the hGH molecule is of a sequential nature in which first binding site 1 of the hGH molecule has to be loaded to allow binding site 2-mediated association of a second receptor or binding protein molecule, mAb 7B11 should be able to prevent the association with the second rhGHBP molecule at sufficiently high concentrations of the mAb, retaining association of hGH biotinyl-rhGHBP on binding site 1 and thereby $50 \%$ of the maximally detectable signal. In contrast, mAb $8 \mathrm{~B} 11$ prevented association at binding site 1 and, therefore, also abolished the

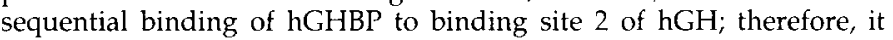
should be able to displace the entire signal derived from the association of biotinyl rhGHBP with hGH.

\section{Results}

\section{Epitope specificity of anti-hGH mAb $7 B 11$}

Cross-reactivity of mAb 7B11 to hGH-related molecules derived from comparison of $50 \%$ intercepts in competitive displacement experiments with increasing concentrations of the respective hGH variant or hGH fragment is shown in Table 1 . The relative displacing potency of $\mathrm{rhGH}$ was set at $100 \%$. Of the hGH fragments tested, mAb 7B11 shows a high degree of cross-reaction with fragment 1-134, representing roughly the first two thirds of the hGH sequence. A minor cross-reaction of $0.84 \%$ was detected with the fragment spanning amino acid residues 15-125; the other tested hGH fragments were not recognized by this mAb.

Twenty-two-kilodalton pituitary-derived hGH (AFP4793B) showed $53.3 \%$ binding potency compared to recombinant 22-kDa hGH. Twenty-kilodalton hGH (AFP-4286B) derived from pituitary extract exhibited $45.7 \%$ cross-reaction, corresponding to $86 \%$ displacing potency of pituitaryderived 22-kDa hGH. hPL, which shares $85 \%$ amino acid homology with hGH, has only $0.94 \%$ cross-reaction with $\mathrm{mAb} 7 \mathrm{~B} 11$, indicating that the epitope recognized by this antibody has a high degree of heterology between hPL and 22-kDa hGH.

Neither N-terminally truncated variants lacking the first 7 or 13 amino acid residues showed any cross-reaction with this $\mathrm{mAb}$, indicating that its binding site overlapped or was near to the N-terminus of the hGH molecule. Finally, the hGH-CV variant showed $22.9 \%$ relative displacing potency, indicating that the epitope bound by $\mathrm{mAb} 7 \mathrm{~B} 11$ might have one amino acid heterology compared to $22-k D a$ hGH. Figure 2 shows a model of hGH in which the structural deviations from $22-\mathrm{kDa}$ hGH of the des ${ }^{7} \mathrm{hGH}$ molecule and the hGH-CV variant are indicated. The ellipse shows binding site 2 , as

TABLE 1. Cross-reaction of hGH-related molecules and hGH fragments with mAb $7 \mathrm{~B} 11$

\begin{tabular}{lrrrr}
\hline \multicolumn{1}{c}{ hGH variants } & & \multicolumn{3}{c}{ hGH fragments } \\
\hline rhGII $(22 \mathrm{kDa})_{\text {rhGH des }^{7}}$ & $100.00 \%$ & aa & $20-40$ & $<0.01 \%$ \\
rhGH des $^{13}$ & $<0.01 \%$ & aa & $1-134$ & $22.50 \%$ \\
rhGH CV & $<0.01 \%$ & aa & $15-125$ & $0.84 \%$ \\
Pituitary hGH & $22.90 \%$ & aa & $95-134$ & $<0.01 \%$ \\
Pituitary hGH $(20 \mathrm{kDa})$ & $53.30 \%$ & aa & $126-170$ & $<0.01 \%$ \\
hPL & $45.70 \%$ & aa & $135-191$ & $<0.01 \%$ \\
\hline
\end{tabular}

Wild-type $22-\mathrm{kDa}$ rhGH was used as reference and arbitrarily assigned $100 \%$ reactivity. aa, Amino acids. 


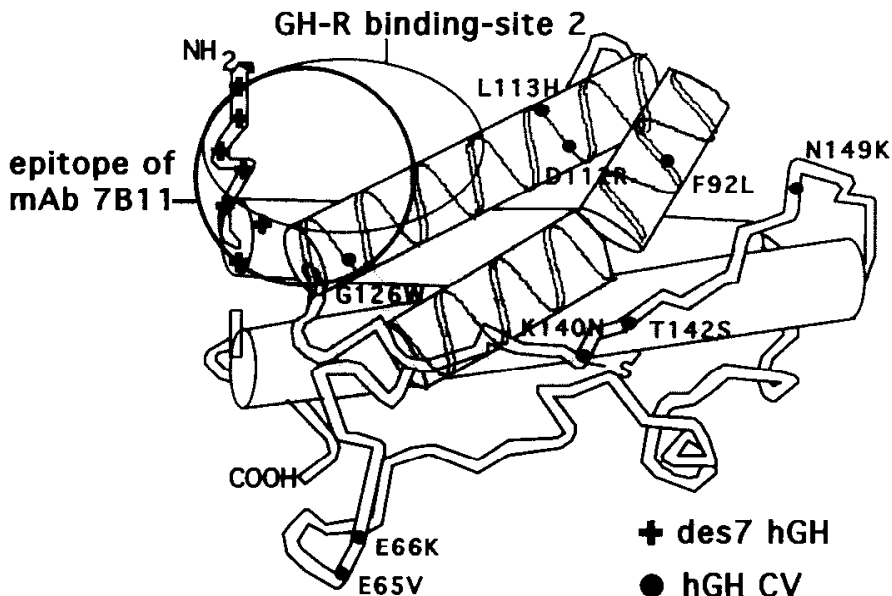

Fig. 2. Binding epitope of mAb 7B11 projected onto the x-ray crystallographically derived structure of the $\mathrm{GH}$ molecule adapted from the report of Abdel-Meguid et al. (24). The filled plus symbols indicate the amino acid residues missing in the des ${ }^{7}$ variant of rhGH; the full circles indicate the sites of mutation in the $\mathrm{CV}$ variant of $\mathrm{rhGH}$. The mutations in the rhGH-CV molecule compared to $22-\mathrm{kDa}$ pituitary $\mathrm{hGH}$ are described using the one-letter code for amino acids, stating first the code of the amino acid in the wild-type hGH, then the amino acid position, and last the amino acid introduced instead of the wildtype sequence in the hGH-CV variant. The ellipse depicts binding site 2 of the hGH molecule's interaction with its receptor (GH-R) according to the report if Cunningham et al. (13); the circle represents the epitope of mAb 7B11.

proposed by Cunningham et al. (13); the circle shows the deduced binding epitope of $\mathrm{mAb}$ 7B11.

\section{Functional relevance of $m A b 7 B 11$ binding to $h G H$}

Twenty-two-kilodalton hGH immobilized via mAb $10 \mathrm{~A} 7$ binding an epitope distant from both receptor-binding sites of the hGH molecule was loaded with biotin-labeled rhGHBP, and the displacing potencies of increasing concentrations of $\mathrm{mAb} 7 \mathrm{~B} 11$ and $\mathrm{mAb} 8 \mathrm{~B} 11$ were investigated as described above. mAb $8 \mathrm{~B} 11$ bound within binding site 1 of the hGH molecule. The experiment shows that mAb 7B11 maximally displaced $50 \%$ of the labeled binding protein molecules, in keeping with blocking of binding site 2 . In contrast, increasing concentrations of $\mathrm{mAb} 8 \mathrm{~B} 11$ hindered the association of hGH with rhGHBP on binding site 1 and, therefore, consecutively also on binding site 2 and displaced all labeled rhGHBP. Fifty percent displacement was achieved at $30 \mathrm{ng}$ mAb 8B11/well. Results are shown in Fig. 3.

\section{Sensitivity and assay range}

Figure 4 shows two hGH IFA standard curves obtained by use of pituitary-derived hGH and rhGH (NIBSC 88/624); the mean \pm 1 sD of three independent hGH-IFA standard curves ran in duplicate are displayed. The rhGH preparation was more potent than the pituitary-derived hGH. The lower detection limit (sensitivity), as defined by the mean $\pm 3 \mathrm{SD}$ of a 20 -fold zero standard determination, was $0.05 \mu \mathrm{g} / \mathrm{L}$. The standard curve was linear in a double logarithmic plot of signal over hGH doses up to a concentration of at least 50 $\mu \mathrm{g} / \mathrm{L}$.

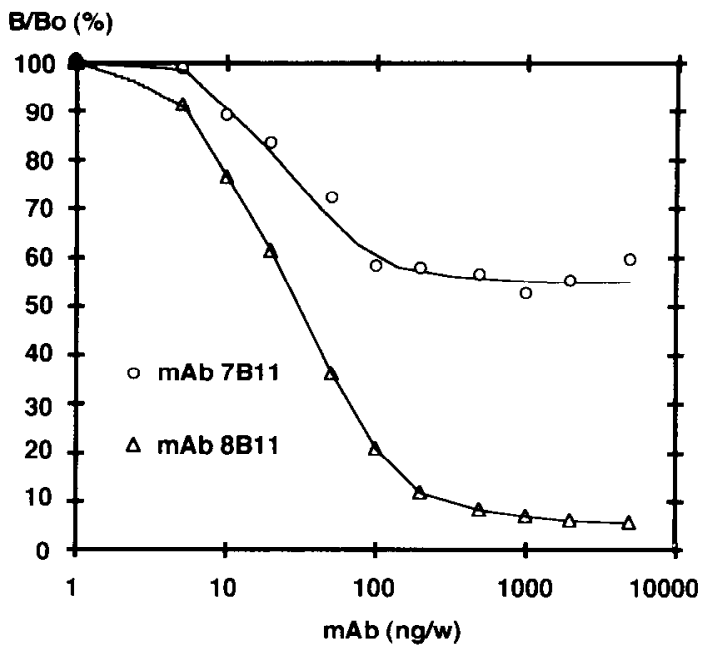

FIG. 3. Displacement of labeled hGHBP from immobilized hGH by increasing concentrations of anti-hGH mAbs. mAb 7B11, which is specific for binding site 2 of the hGH molecule, displaces maximally $50 \%$ of labeled rhGHBP, whereas mAb $8 \mathrm{~B} 11$, directed to binding site 1 of the hGH molecule for the hGH receptor is capable of fully displacing the labeled hGH receptor ecto domain.

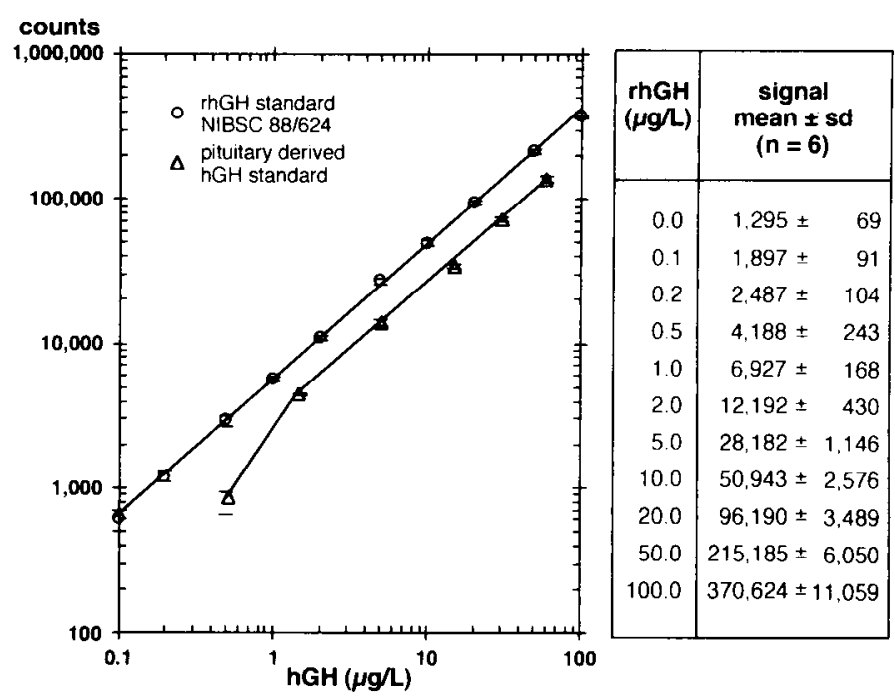

FIG. 4. IFA standard curves for the reference preparation $88 / 624$ of rhGH in sheep serum (circles) and pituitary-derived hGH (triangles). The error bars represent 1 SD of the signal obtained in three independent experiments, the signal obtained by use of rhGH (88/624) is shown as the mean \pm SD for the calibrator concentrations used in the table on the right.

\section{Assay reproducibility}

Within-assay coefficients of variation were determined for three sera in an 18-fold analysis. At concentrations of 0.43 , 5.3 , and $19.2 \mu \mathrm{g} / \mathrm{L}$, the within-assay coefficients of variation were $8.5 \%, 7.3 \%$, and $6.1 \%$, respectively. Between-assay reproducibility was analyzed by measurements of the same sera in eight independent assays. The respective betweenassay coefficients of variation were $12.8 \%, 9.4 \%$, and $7.9 \%$.

\section{Interference of endogenous $h G H B P$ with the $h G H I F A$}

Fixed concentrations of hGH were preincubated with increasing concentrations of rhGHBP. One microgram per $\mathrm{L}$ 
$\mathrm{hGH}$, corresponding to a $45.5 \mathrm{pmol} / \mathrm{L}$ concentration, showed the highest susceptibility to interference from endogenous hGHBP. At $2000 \mathrm{pmol} / \mathrm{L}$ rhGHBP, the detected concentration of hGH was $97 \%$; at $5000 \mathrm{pmol} / \mathrm{L}$ rhGHBP, it was reduced to $56 \%$. Higher concentrations of hGH were less prone to interference. The results of this experiment are shown in Fig. 5. As the physiological concentration of hGHBP in serum samples is approximately $1000 \mathrm{pmol} / \mathrm{L}$ (range, 56-1187 $\mathrm{pmol} / \mathrm{L}$ ) (27), no significant interference was expected from endogenous hGHBP concentrations in hGH results obtained by the IFA following this protocol.

\section{Linearity and recovery}

The linearity of the hGH IFA was evaluated by dilution of serum samples in sheep serum. The results obtained from the IFA were compared to the calculated results. The measured results were within a range of $89-104 \%$ of those expected, with a mean of $97.5 \%$. The detailed linearity results are shown in Table 2.

Recovery was evaluated by mixing equal volumes of different sera with rhGH calibrators in sheep serum and assaying these as unknowns. The measured results were within $94.7 \%$ and $111.7 \%$ of those expected, with a mean \pm sn of $100.5 \pm 7.1 \%$.

\section{Specificity of the assay}

$\mathrm{hPL}$ and $20-\mathrm{kDa} \mathrm{hGH}$, as well as hGH dimers were serially diluted in sheep serum and measured as unknowns in the hGH IFA. Cross-reaction of hPL in the hGH IFA was below $0.001 \% ; 10 \mathrm{mg} / \mathrm{L} \mathrm{hPL}$ gave no detectable signal. Twentykilodalton rhGH showed a relative potency of $0.16 \% \mathrm{com}$ pared to 22-kDa hGH; the dose-response curve was linear in the detectable range between 200-1000 $\mu \mathrm{g} / \mathrm{L}$. Dimers had a relative potency of $111.6 \%$. These specificity data indicate that hPL, which may circulate in extremely high levels during pregnancy, will not interfere in the assay.

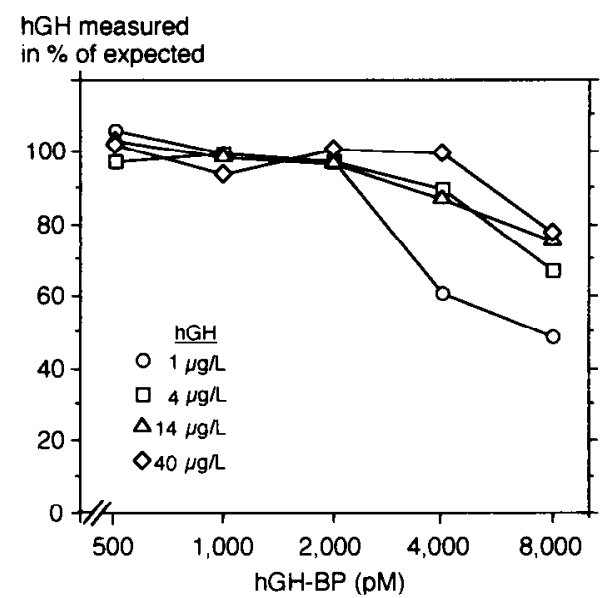

FIG. 5. Interference of endogenous hGHBP with hGH measurements performed by the IFA. Increasing concentrations of rhGHBP were added to fixed concentrations of hGH and preincubated. Thereafter, the samples were analyzed in the IFA, and the results are displayed as the concentration measured as a percentage of that expected. Even at the lowest concentration of hGH tested $(1 \mu \mathrm{g} / \mathrm{L})$, the interference from $h G H B P$ within physiological concentrations $(\leq 2000 \mathrm{pmol} / \mathrm{L}$ ) was a negative bias of below $3 \%$.
TABLE 2. Linearity of two patient sera determined in the hGH IFA

\begin{tabular}{lccc}
\hline Serum samples & Measured $(\mu \mathrm{g} / \mathrm{L})$ & Expected $(\mu \mathrm{g} / \mathrm{L})$ & \% of expected \\
\hline Serum 1, direct & 4.51 & & \\
$1: 2$ & 2.35 & 2.25 & 104.2 \\
$1: 4$ & 1.11 & 1.13 & 98.4 \\
$1: 8$ & 0.50 & 0.56 & 88.7 \\
$1: 16$ & 0.29 & 0.28 & 102.9 \\
Serum 2, direct & 62.80 & & \\
$1: 2$ & 31.60 & 31.40 & 100.6 \\
$1: 4$ & 14.42 & 15.70 & 91.8 \\
$1: 8$ & 7.45 & 7.85 & 94.9 \\
$1: 16$ & 3.87 & 3.92 & 98.6 \\
Mean \pm SD & & & $97.5 \pm 5.4$ \\
\hline
\end{tabular}

\section{Comparison of hGH IFA with polyclonal hGH RIA}

We decided to compare the hGH-IFA to the polyclonal competitive RIA because the latter method is the most widely applied technique for hGH measurement worldwide and is assumed to yield comparable results between different laboratories. When comparing the results from 128 serum samples from different patients between the hGH IFA and the RIA, both using rhGH as the standard, the IFA yielded, on the average, $73.2 \%$ of the concentration determined by the RIA (Fig. 6A). This result indicates that serum samples, on the average, contain $27 \%$ of molecular forms of hGH that are recognized by RIA, but do not express both binding sites 1 and 2 as measured in the IFA. When replacing the standard used in the RIA by pituitary-derived hGH, as most commonly used throughout, and comparing the results to those from the IFA calibrated again by rhGH, the IFA detects, on the average, $30 \%$ of the RIA result (Fig. $6 \mathrm{~B}$ ). The major contribution to this heterology, as deduced from comparing Fig. 6 , A and $\mathrm{B}$, is contributed by the heterology of standards; the remainder is determined by the existence of bioinactive $\mathrm{hGH}$ forms. The scatter of individual samples around the regression line in the latter regression analysis is reflected by a correlation coefficient of $\mathrm{r}^{2}=0.869$, indicating that the degree of bioinactive hGH forms in circulation differs between individuals. On an individual basis, the degree of immunofunctionally active $\mathrm{hGH}$ forms in serum samples, as calculated by comparison of IFA and RIA results from assays both using rhGH as calibrators (Fig. 6A), varied between $52-93 \%$.

\section{Comparison of hGH IFA with Nb2 cell bioassay}

Eighteen sera collected for GH determination in the Section of Pediatric Endocrinology at the Universitäts-Kinderklinik (Tubingen, Germany) were selected to cover a range between $1.0-25.8 \mu \mathrm{g} / \mathrm{L}$ by RIA. These sera were analyzed additionally in the $\mathrm{Nb} 2$ cell assay and by IFA. The correlation between RIA and Nb2 cell assay, both calibrated against pituitary-derived hGH IRP 80/505, was $\mathrm{r}^{2}=0.84$, with a regression line equation of $y_{(\mathrm{Nb} 2)}=0.39+0.89 x_{(\mathrm{RIA})}$. IFA results, derived from calibration with recombinant International Reference Preparation 88/624, compared to RIA with $r^{2}=0.88$ and a regression line of $y_{(\mathrm{IFA})}=0.04+0.54 x_{(\mathrm{RIA})}$. The agreement between Nb2 cell assay and the hGH IFA, as shown in Fig. 7, was higher than that of either of the methods compared to RIA, with $\mathrm{r}^{2}=0.97, y_{(\mathrm{Nb2})}=-0.04+0.58 x_{(\mathrm{IFA})}$. 

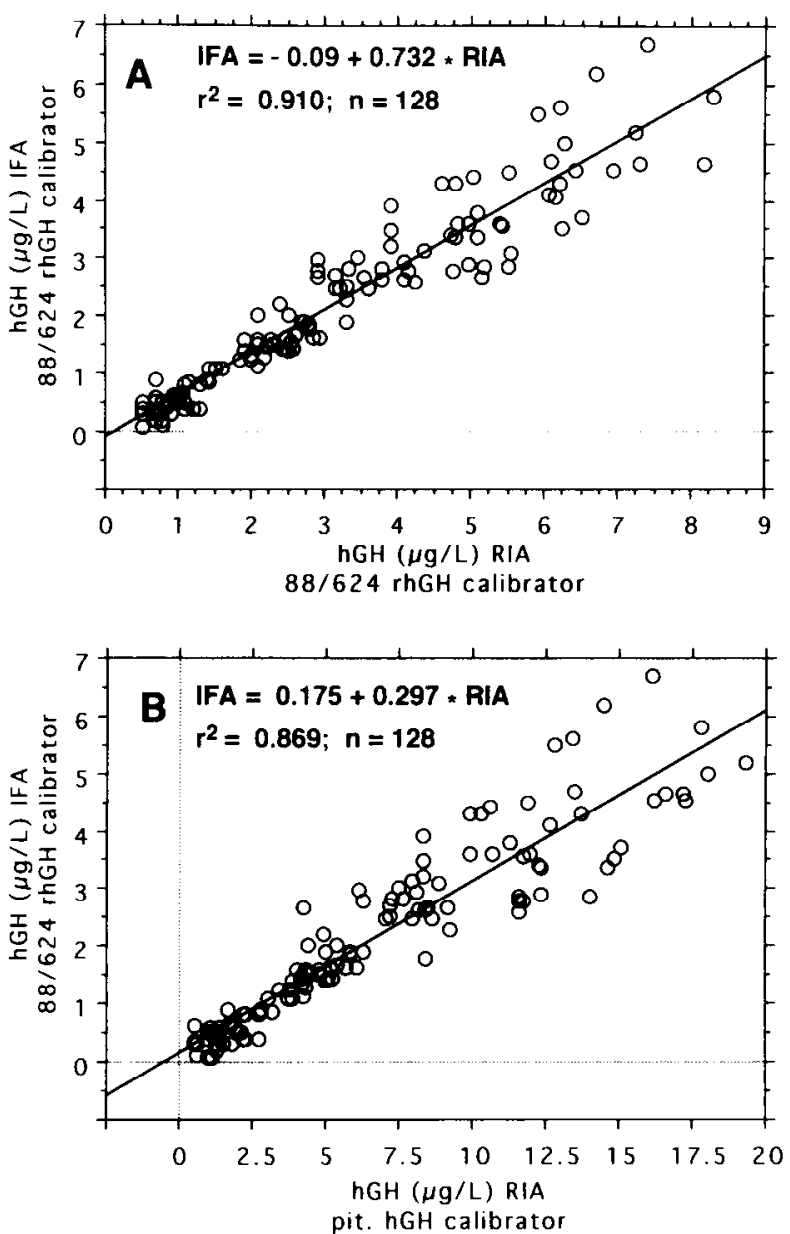

FIG. 6. Correlation of hGH measurements by RIA and IFA in 128 sera selected from basal and stimulated sera of adult patients on the basis of their RIA result being within the detectable range of the RIA $(\geq 0.5 \mu \mathrm{g} / \mathrm{L})$ and in the major clinical range of interest $(\leq 20 \mu \mathrm{g} / \mathrm{L})$. The latter criterion was chosen to avoid calculation of a biased regression line by single high sample points. In $A$, results are compared by use of rhGH (88/624) in both assays; in B, results from the IFA calibrated with rhGH are compared to those from a polyclonal hGH RIA using pituitary-derived calibrators.

\section{Clinical application of the hGH IFA}

The hGH levels determined in arginine infusion tests conducted for the investigation of suspected GH deficiency in adults are displayed in Fig. 8 for six patients who had previously undergone pituitary surgery for nonfunctioning adenomas and who required replacement therapy with glucocorticoids, $\mathrm{T}_{4}$, and gonadal steroids. In the same figure, for comparison, the results of arginine-induced GH secretion in two healthy volunteers are displayed (the two upper lanes).

hGH levels were also analyzed by IFA and RIA in acromegalic patients before and in hourly intervals for $8 \mathrm{~h}$ after application of a single dose of $100 \mu \mathrm{g}$ somatostatin (Octreotide, Sandoz, Basel, Switzerland). In patients with residual activity of acromegaly after transsphenoidal surgery for a somatotropin-producing adenoma, both methods showed the expected decay in GH levels after the drug application to between $30-45 \%$ of baseline (data not shown). The ratio between the results measured in the RIA and those determined by IFA did not change significantly during this phar-

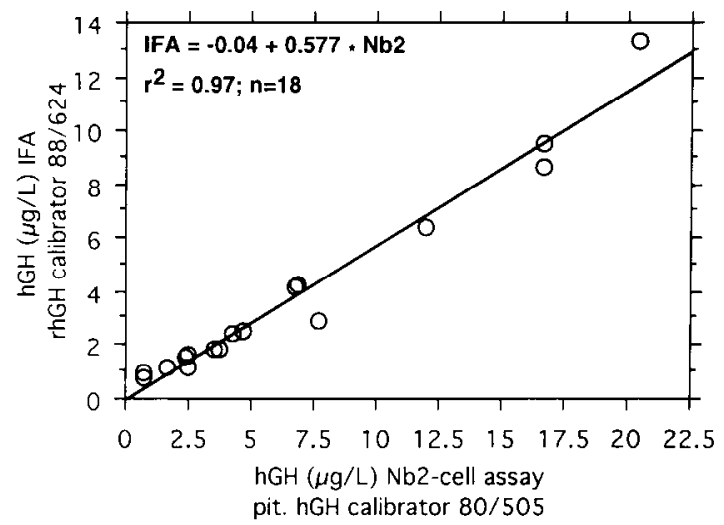

FIG. 7. Correlation of hGH measurements obtained by the Nb2 cell assay (26) and the hGH IFA. Eighteen sera were selected on the basis of hGH concentration, determined by RIA to cover a range between $1.0-25.8 \mu \mathrm{g} / \mathrm{L}$.

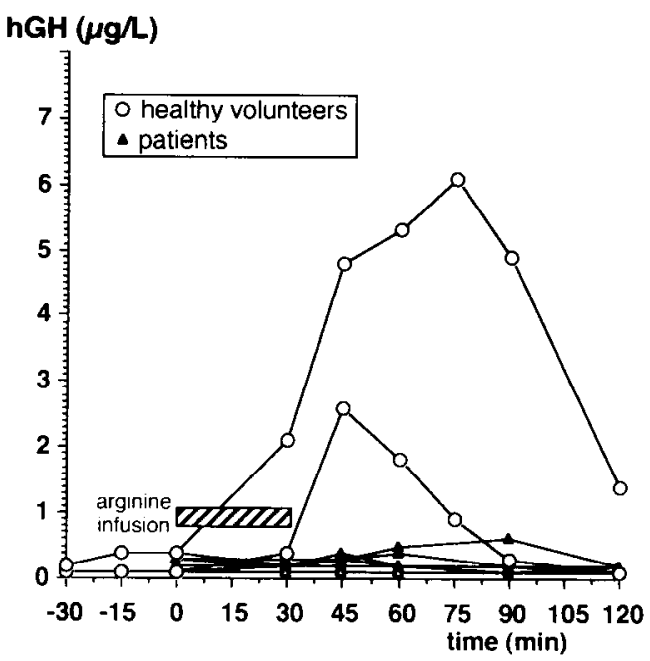

FIG. 8. hGH levels measured by IFA in arginine stimulation tests in six patients with hypopituitarism after transsphenoidal surgery for nonfunctioning pituitary adenoma (triangles) and in two healthy controls (circles).

macokinetic study and was in keeping with the results of the regression analysis shown in Fig. 6 .

\section{Discussion}

We described the development of an immunofunctional assay for the measurement of GH levels in human blood. In this sandwich-type assay, only those molecular forms of GH that possess both binding sites 1 and 2 for the GH receptor generate an assay signal. This is accomplished by immobilization of a monoclonal antibody binding to binding site 2 of hGH and the use of labeled rhGHBP to bind binding site 1 of the hGH molecule. The use of rhGHBP rather than a second monoclonal antibody to $\mathrm{GH}$ is essential for this purpose, because only the structural identity of hGHBP with the hGH receptor allows for the accurate monitoring of GH's capability of binding to its receptor. As an epitope recognized by a monoclonal antibody spans over a maximum of 10 amino acid residues (20), a monoclonal antibody could not representatively mimic the interaction of $\mathrm{GH}$ with its recep- 
tor on binding site 1 , which involves 31 amino acid sidechains (18).

The immunofunctional hGH assay is suitable for clinical routine use, as characterized by its working range between $0.1-100 \mu \mathrm{g} \mathrm{hGH} / \mathrm{L}$. We have shown that endogenous GHBP levels in physiological concentrations do not result in significant interference with the hGH results derived from the IFA method. By comparison of results from 128 sera measured in both a competitive polyclonal RIA using the same rhGH reference preparation $88 / 624$ and the IFA, it can be concluded that, on the average, $27 \%$ of molecular forms in circulation give rise to a signal in the RI $\Lambda$, but not in the IFA. From the design of the IFA, we conclude that these $27 \%$ of $\mathrm{hGH}$ forms in circulation do not possess both binding sites for the receptor and, therefore, would not be able to initiate a signal transduction process at target cells, which is known to require receptor dimerization. When comparing the results obtained by use of the IFA and rhGH as the calibrator to those obtained from polyclonal RIA calibrated by use of pituitary hGH, the IFA results were, on the average, only $30 \%$ of those from the RIA. The major contribution to this discrepancy, however, is from the different potencies of the calibrators. Direct comparison of RIA results obtained by use of pituitary-derived $v s$. recombinant calibrator shows a decline in hGH levels to less than $50 \%$. The remainder of the discrepancy between IFA and RIA results accounts for molecular forms not recognized in the IFA, but giving a signal in the RIA.

One possible limitation of the method is its relative overestimation of hGH dimers. After binding to the immobilized $\mathrm{mAb}$ $7 \mathrm{~B} 11$, some of the hGH dimer molecules appear to be capable of binding two labeled hGH receptor ecto domains (hGHBP). An interesting observation was that recombinant $20-\mathrm{kDa} \mathrm{hGH}$ showed a dose-response curve parallel to that of $22-\mathrm{kDa} \mathrm{hGH}$, but with a potency of only $0.16 \%$ relative to that of $22-\mathrm{kDa} h \mathrm{hH}$. The existing body of literature is controversial as to whether 20-kDa hGH can activate the GH receptor. hPL, the concentration of which in late pregnancy is known to exceed that of $\mathrm{GH}$ by a factor of 1000 , shares $85 \%$ amino acid homology with hGH. At concentrations up to $10 \mathrm{mg} / \mathrm{L}, \mathrm{hPL}$ does not result in a measurable signal in the hGH IFA.

The use of biotin as a primary probe in the IFA described here allows for versatile end-point determination; the streptavidin-europium conjugate used by us can easily be replaced by a streptavidin-enzyme conjugate for colorimetric end-point determination or any other label attached to streptavidin for which a laboratory is equipped with the respective measurement device. This, in principle, allows for application of the IFA in any endocrine laboratory.

Theoretically, bioassays, although more cumbersome in performance, could provide reliable estimates of biologically active GH levels in serum. The results of hGH determinations by bioassays, however, have to be interpreted with caution, bearing in mind that in these systems the interaction of hGH with receptors of other species, mostly rat GH receptors (28) or rat PRL receptors (29), is monitored. The employment of hGH receptors as expressed on IM9 cells in a competitive binding assay is limited by a lower detection limit of $\sim 2$ $\mu \mathrm{g} / \mathrm{L} \mathrm{(30)}$ due to the rather low affinity of the hGH receptor for its specific ligand, which is on the order of $1 \mathrm{nmol} / \mathrm{L}$.
Liver membrane RRAs lack specificity for hGH (31). The $\mathrm{Nb} 2$ cell assay (26), which employs rat lymphoma cells expressing a short form of the rat PRL receptor with a higher affinity for $\mathrm{hGH}$ than the $\mathrm{hGH}$ receptor with a $\mathrm{K}_{\mathrm{a}}$ of $1 \times 10^{10} \mathrm{~L} / \mathrm{mol}$ appears to be the sole bioassay for hGH that can be performed with tolerable effort in large scale sample series and provides sufficient sensitivity to measure $\mathrm{GH}$ levels in the relevant clinical range down to 0.1 $\mu \mathrm{g} / \mathrm{L}$. In Fig. 7, we show very good agreement between the results of the $\mathrm{Nb} 2$ cell assay and the hGH IFA in 18 sera. Whether the agreement between the two methods is as high in all instances remains to be investigated by larger series of samples. Potential discrepant results from the $\mathrm{Nb} 2$ cell assay and the hGH IFA could be explained by the fact that the $\mathrm{Nb} 2$ cell assay studies the interaction of $\mathrm{GH}$ with a heterologous receptor and requires blocking of endogenous PRL by the addition of a neutralizing antibody. Independently of these theoretical concerns, the performance and handling of the hGH IFA are substantially easier than those of the $\mathrm{Nb} 2$ cell assay because living cells are not used, even though an elegant modified version of the $\mathrm{Nb} 2$ cell assay has recently been described in this journal by Dattani et al. (32).

The high degree of heterogeneity in results of hGH measurements performed by different immunoassays (1) poses a major problem in the standardization of cut-off levels for $\mathrm{GH}$ provocative testing. Until now, the highest degree of comparability between results from different laboratories was achieved by application of polyclonal competitive immunoassays. As a consequence of the variations in specificity of the antibodies employed, results differ even between these assays.

As the diagnosis of GH deficiency results in GH replacement therapy, which implies the need for daily sc injections for the patient and substantial cost for the health care system, transparent and standardized diagnostic criteria have to be postulated for the establishment of this diagnosis. Determination of $\mathrm{GH}$ levels in provocative tests presently is required for confirmation of the diagnosis and in many countries also for the reimbursement of therapy costs. We, therefore, consider crucial the standardization of the assay procedure and reference preparation used.

For the purpose of harmonization of immunoassay measurements of hGH levels, a consensus has to be achieved with respect to the reference preparation of hGH used for calibration of these methods. Recombinant 22-kDa hGH has recently become available as an international reference preparation and represents a homogeneous, well defined hGH standard. For elimination of heterogeneity in assay results that are attributed to differences in epitope specificities, we propose the IFA method as a possible gold standard for hGH quantitation.

We are currently using the IFA to establish empirical cutoff levels in hGH provocative testing by insulin tolerance test and arginine infusion. Additionally, we intend to address the question of changes in the ratio between immunoassayable and immunofunctionally active forms of hGH in different dynamic tests. 


\section{Acknowledgments}

We thank Drs. A. Gertler and G. Crivi for providing recombinant hGI IBP, Dr. P. Gellerfors for the hGH-CV variant, Eli Lilly (Indianapolis, IN) for recombinant forms of hGH, Drs. A. F. Parlow and S. Raiti (NIDDK) for pituitary-derived GH preparations and polyclonal antihGH antibodies, Dr. J. Kostyo for hGH fragments, and Drs. M. W. Elmlinger and M. B. Ranke (Tubingen, Germany) for performance of $\mathrm{Nb} 2$ cell assays and permission to quote collaborative results.

\section{References}

1. Granada ML, Sanmarti A, Lucas A, et al. 1990 Assay-dependent results of immunoassayable spontaneous 24-hour growth hormone secretion in short children. Acta Paediatr Scand. 370(Suppl):63-70.

2. Levin PA, Chalew SA, Martin L, Kowarski AA. 1987 Comparison of assays for growth hormone using monoclonal or polyclonal antibodies for diagnosis of growth disorders. J Lab Clin Med. 109:85-88.

3. Reiter EO, Morris AH, MacGillivray MH, Weber D. 1988 Variable estimates of serum growth hormone concentrations by different radioassay systems. J Clin Endocrinol Metab. 66:68-71.

4. Celniker AC, Chen AB, Wert RJ, Sherman BM. 1989 Variability in the quantitation of circulating growth hormone using commercial immunoassays. J Clin Endocrinol Metab. 68:469-476.

5. Baumann G. 1990 Growth hormone binding proteins and various forms of growth hormone: implications for measurements. Acta Paediatr Scand. 370(Suppl):72-80.

6. Baumann G. 1991 Growth hormone heterogeneity: genes, isohormones, variants, and binding proteins. Endocr Rev. 12:424-449.

7. Strasburger CJ. 1994 Implications of investigating the structure-function relationship of human growth hormone in clinical diagnosis and therapy. Horm Res. 2:113-119.

8. Felder RA, Holl RW, Martha PJ, et al. 1989 Influence of matrix on concentrations of somatotropin measured in serum with commercial immunoradiometric assays. Clin Chem. 35:1423-1426.

9. Ranke MB, Stoleke H, ed. 1994 Diagnostik des Wachstumshormonmangels. Aktuelle methodische und klinische Aspekte. Ankum-Kettenkamp: Verlag DOKUMENT + BILD.

10. Rosenfeld RG, Albertsson-Wikland K, Cassorla F, et al. 1995 Diagnostic controversy: the diagnosis of childhood growth hormone deficiency revisited. J Clin Endocrinol Metab. 80:1532-1540.

11. Hoffman DM, O'Sullivan AJ, Baxter RC, Ho KK. 1994 Diagnosis of growthhormone deficiency in adults. Lancet. 343:1064-1068.

12. Strasburger CJ. 1990 Antigenic epitope mapping of the human growth hormone molecule: a strategy to standardize growth hormone immunoassays. Acta Paediatr Scand. 370(Suppl):82-86.

13. Cunningham BC, Ultsch M, deVos AM, et al. 1991 Dimerization of the extracellular domain of the human growth hormone receptor by a single hormone molecule. Science. 254:821-825.

14. Silva CM, Day RN, Weber MJ, Thorner MO. 1993 Human growth hormone
(GH) receptor is characterized as the 134-kilodalton tyrosine-phosphorylated protein activated by GH treatment in IM-9 cells. Endocrinology, 133:2307-2312.

15. Carter SC, Argetsinger LS, Campbell GS, et al. 1994 The identification of JAK2 tyrosine kinase as a signaling molecule for growth hormone. Proc Soc Exp Biol Med. 206:210-215.

16. Lebrun JJ, Ali S, Ullrich A, Kelly PA. 1995 Proline-rich sequence-mediated Jak2 association to the prolactin receptor is required but not sufficient for signal transduction. J Biol Chem. 270:10664-10670.

17. de Vos A, Ultsch M, Kossiakoff AA. 1992 Human growth hormone and extracellular domain of its receptor: crystal structure of the complex. Science. 255:306-312.

18. Clackson T, Wells JA. 1995 A hot spot of binding energy in a hormone-receptor interface. Science. 267:383-386.

19. Barnard R, Rowlinson SW, Brinkworth R, et al. 1994 The search for receptorinteractive regions in growth hormone: historical perspectives and novel strategies. Acta Paediatr. 399(Suppl):33-41.

20. Jin L, Fendly BM, Wells JA. 1992 High resolution functional analysis of antibody-antigen interactions. J Mol Biol. 226:851-865.

21. Köhler G, Milstein C. 1976 Derivation of specific antibody-producing tissue culture and tumor lines by cell fusion. Eur J Immunol. 6:511-519.

22. Strasburger CJ, Kohen F. 1990 Two-site and competitive chemiluminescent immunoassays. Methods Enzymol. 184:481-496.

23. Strasburger CJ, Kostyo J, Vogel T, Barnard GJ, Kohen F. 1989 The antigenic epitopes of human growth hormone as mapped by monoclonal antibodies. Endocrinology. 124:1548-1557.

24. Abdel-Meguid SS, Shieh HS, Smith WW, et al. 1987 Three-dimensional structure of a genetically engineered variant of porcine growth hormone. Proc Natl Acad Sci USA. 84:6434-6437.

25. Salacinski PR, McLean C, Sykes JE, Clement JV, Lowry PJ. 1981 lodination of proteins, glycoproteins, and peptides using a solid-phase oxidizing agent 1,3,4,6-tetrachloro-3alpha,6alpha-diphenyl glycoluril (lodogen). Anal Biochem. 117:136-146.

26. Tanaka T, Shiu RP, Gout PW, et al. 1980 A new sensitive and specific bioassay for lactogenic hormones: measurement of prolactin and growth hormone in human serum. J Clin Endocrinol Metab. 51:1058-1063.

27. Mercado M, Carlsson L, Vitangcol R, Baumann G. 1993 Growth hormonebinding protein determination in plasma: a comparison of immunofunctional and growth hormone-binding assays. J Clin Endocrinol Metab. 76:1291-1294.

28. Ellis S, Vodian MA, Grindeland RE. 1978 Studies on the bioassayable growth hormone-like activity of plasma. Recent Prog Horm Res. 34:213-238.

29. Peabody CA, Schultz PN, Warner MD, et al. 1992 Prolactin bioassay and hyperprolactinemia. J Endocrinol Invest. 15:49\%-499.

30. Gavin J, Trivedi B, Daughaday WH. 1982 Homologous IM-9 lymphocyte radioreceptor and receptor modulation assays for human serum growth hormone. J Clin Endocrinol Metab. 55:133-139.

31. Daughaday WH, Trivedi B, Winn HN, Yan H. 1990 Hypersomatotropism in pregnant women, as measured by a human liver radioreceptor assay. J Clin Endocrinol Metab. 70:215-221.

32. Dattani MT, Hindmarsh PC, Brook CG, et al. 1993 Enhancement of growth hormone bioactivity by zinc in the eluted stain assay system. Endocrinology. 133:2803-2808. 